\title{
A review of V2-X solutions by investigating different Vehicle Energy Storage Solutions for Nearly Zero Energy Buildings
}

\author{
Yasaman Balali $^{1}$ and Sascha Stegen ${ }^{1}$ \\ ${ }^{1}$ School of Engineering, Griffith University, Brisbane, QLD 4111, Australia \\ Yasaman.Balali@griffithuni.edu.au \\ S.Stegen@griffith.edu.au
}

\begin{abstract}
Combining sustainable electric vehicle (EV) technologies with renewable energy sources in building and tran sportation sectors is an effective approach for reducing energy consumption, in order to meet nearly zero energy buildings (NZEBs) concepts. To this end, the integration of EVs through bidirectional converters with smart buildings, which are supplied by renewable energy sources such as photo-voltaic systems, has gained noticeable attention from researchers around the world. In order to meet and optimize the energy requirement of smart buildings with V2G-H-B (V2-X), which includes vehicle-to-home (V2H), vehicle-to-building (V2B) and vehicle-to-grid (V2G) technologies, an energy management strategy is needed. Plug-in battery-based EVs, plug-in hybrid EVs, and hydrogen fuel cell EVs are automobiles proposed for implementing the integrative approaches. The main purposes of this study are to review the proposed approaches for the integration of smart buildings and EVs, in order to introduce the possible future integration of hybrid fuel cell-based EVs to buildings and power grids. Previous studies demonstrated the limitations of battery life, because of the large number of charging and discharging requirements, which cause battery degradation. Wireless converters or wire connected bidirectional converters, are the components which are required for transferring energy from vehicle to grid/building/home, vice versa. This study will suggest the use of hydrogenbased hybrid electric vehicles as an energy transfer or in V2-X solutions.
\end{abstract}

Keywords: vehicle-to-home/building/grid, plug-in electric vehicles, hydrogen fuel cell electric vehicles, nearly zero energy buildings.

\section{Introduction}

Building energy performance enhancement as a solution for reducing energy demand and increasing sustainability, led to the introduction of the nearly zero energy buildings (NZEB) concepts, which evaluate whether the annual generated energy by renewable resources is matching annual building energy demand from the power grids [1]. The integration of electric vehicles (EVs) with buildings as an alternative source of energy provider has a significant role to play in reducing energy consumption, in order to move toward NZEB [2], and reducing power grid dependency [3]. The developments in home 
energy management systems (EMSs) and smart meters for infrastructures have been essential to evaluating the energy demand response and suggesting the optimal use of home appliances [4]. EVs can operate in various modes, such as vehicle-togrid/home/building (V2G-H-B/V2X) and G-B-H2V, while a noticeable reduction in power losses caused by long-distance transmission lines in $\mathrm{V} 2 \mathrm{G}$ systems is achieved through the use of $\mathrm{V} 2 \mathrm{H}$ [5]. Plug-in electric vehicles (PEVs) are a common configuration for V2H-B options with a need for bidirectional energy flow between the vehicle and house/building [6,7]. The connection of the EV to the home can be utilized for recharging the battery or transferring the stored energy in the battery to the home loads which introduces the $\mathrm{H} 2 \mathrm{~V}$ and $\mathrm{V} 2 \mathrm{H}$ concepts [8, 9]. Heating, ventilation, and air conditioning (HVAC) systems consume high amount of energy in buildings. Therefore, consideration of HVAC as well as other appliances are important to evaluate whether V2X systems are beneficial approaches for meeting the NZEB concepts.

In order to find the best-optimized solution which can increase the battery life of EVs integrated to homes/buildings, this paper review the concepts and experiments implemented in this area. Moreover, the technology of PEVs as well as hydrogen fuel cell EVs are reviewed for their potential to be connected to power grid and buildings. This study is divided into sections focusing on V2X solutions, with a short explanation of V2G concept as the primary investigation of using EVs as energy suppliers and the prominent focus on buildings and homes. Followed by a short case study of different types of bidirectional converters are used in these systems. Furthermore, various suitable EVs, which can be suitable for these technologies are introduced.

\section{V2G solution}

The introduction of the smart grid has made a significant contribution toward connecting EVs to the grid, in order to benefit from using reactive power consumption, regulating the power network, spinning reverse functionality (provision of extra energy generation for unplanned load demand [10]), and shifting the required energy demand from peak-load to off-peak-load [11, 12]. The prominent components for V2G/G2V technologies are EVs, aggregator controllers, with the responsibility of controlling the safety of charging and discharging of batteries, as well as charging and discharging equipment [13]. In order to convert power from $\mathrm{AC}$ to $\mathrm{DC} / \mathrm{DC}$ to $\mathrm{AC}$, a bidirectional converter needs to be added to the infrastructure [14], which can support the active power required from the grid by managing the load peak demand [11]. In bidirectional category, based on the state-of-charge (SOC) level in a battery, EVs are acting as mobile energy storage and can be charged from the grid or supply the energy back to the grid [14]. In this technology, the local controller collects energy from different EVs and manage energy flow without negative influences on EVs and power grid operations [13].

\section{$3 \quad$ V2H and V2B technologies}

The V2H concept refers to the storage of extra generated energy in the battery of a vehicle during off-peak hours to reuse it as a source of power during peak demand [15]. 
Additionally, V2H-B can be considered as the backup energy source in the situation of a power outage or grid failure [16], when EV acts as a voltage source to supply power for the home [17]. On the positive side, fewer complex transmission line structures from the grid, higher level of grid stability, and lower grid energy requirement are achieved in V2H [18]. Conversely, the grid power losses, stabilization of load, and demand for energy should be taken into consideration in this technology [19]. The minimum components required for $\mathrm{V} 2 \mathrm{H}$ technology are an $\mathrm{EV} / \mathrm{PEV}$, a bidirectional charger, smart meters, home EMSs, home electric appliances, and a small-scale distributed energy generation [20,21]. The combination of renewable energy sources with EVs as a power source in homes/buildings can increase energy efficiency [7, 15]. Based on the SOC level in the battery of EV, electrical appliances receive energy as long as the vehicle is plugged into the smart home, using the uninterruptible power supply (UPS) [22]. V2H applications can be authorized for both linear and nonlinear electric appliances and contain two divisions which are the use of EV in isolated systems as a voltage source and its operation in the grid-connected case as offline UPS respectively [23]. The ACDC/DC-AC and DC-DC power converters, which are part of bidirectional EV chargers are connected to a DC-link in V2H systems [22]. The DC-AC converter section has the functionality of working as a voltage source with four-quadrant conversion static synchronous compensator (STAT-COM) functionality and can control the frequency and amplitude of $50 \mathrm{~Hz}$ loads in addition to synthesizing with the grid voltage. At the same time, the DC-link regulation is conducted by the DC-DC converter section [22]. Moreover, if the vehicle is connected to home, both converters act as an AC-DC/DC-AC converter, which can switch quickly between $\mathrm{H} 2 \mathrm{~V} / \mathrm{V} 2 \mathrm{H}$ modes $[21,24]$. The notion of $\mathrm{V} 2 \mathrm{H}-\mathrm{B}$ can be extended to multiple numbers of houses and buildings providing EVs and roof-mounted PV systems with the advantages of a wide-spreading provision of energy to other grid-connected houses [25].

In building-to-vehicle-to-building $\left(\mathrm{V}^{2} \mathrm{~B}^{2}\right)$ solution, the energy is exchanged among different buildings by EVs [26]. This concept for the first time considered an office located in another building in addition to the V2H technology, and was proposed in [19]. The comparison between the proposed cases for ${\mathrm{V} 2 \mathrm{~B}^{2}}^{2}$ in [19], demonstrated that the existence of swappable extra battery pack with that of EV in the selected home, which has roof mounted PV systems reduced the required energy [19].

The sensitivity analysis of $\mathrm{V}_{2} \mathrm{~B}^{2}$ scheme in Naples, Italy with Mediterranean climate is conducted in [26], with the prominent idea of exploiting the off-site renewable energy from smart home via EV, which transfers battery stored energy to buildings. In this investigation, the office in the building, as well as the home both, have HVAC systems and appliances, while the installation of building-integrated PV panels is on the tilted roof of the home or south façade of the office. And the swappable battery packs are located inside the home. It is concluded that the highest percentage of energy-saving is related to the situation when the battery swap option was added and the PV panels were installed in the home [26].

An integrated FCEV to grid system including $4 \mathrm{~kW}$ PV panels, a residential house, and Hyundai $\mathrm{ix} 35^{\circledR}$ as a FCEV with a hydrogen storage capacity of $5.6 \mathrm{~kg}$ was conducted and tested during winter time in a village situated in the Netherlands [27]. The main difference in FCEV is that in addition to battery energy, the remaining energy from the chemical conversion of hydrogen to electricity would be sent back to the 
grid/house/building. The proposed scenario concluded that from $3 \mathrm{~kW}$ up to $10 \mathrm{~kW}$ electricity production of FCEV was efficient; however, hydrogen requirement increased linearly with a rose in power output [27].

\subsection{Bidirectional EV chargers and Wireless systems}

The bidirectional charger combined in PEVs, permits the transmission of power in both directions (V2H and H2V) [28]. Different types of bidirectional chargers such as DCDC converters, high gain non-isolated converters, and isolated converters are reviewed in [29]. These converters charge the battery of the vehicle in low SOC by the power grid or by home renewable energy sources, while the energy can be transferred back to the grid/home in high SOC of the battery [28]. The DC-DC half-bridge converter functions as a buck converter, which controls the battery current in charging mode and operates as a boost converter in discharging mode [23]. With these converters, a lithiumIon battery of the EV charges up to $80 \%$ of the battery capacity under constant current and then charges the remaining $20 \%$ with constant voltage [23].

The difficulties and complicated configuration of these wire-dependent, conventional bidirectional $\mathrm{V} 2 \mathrm{H}$ systems resulted in the design of wireless topologies [30, 31]. Wheel wireless charging systems are installed in the tyre of the wheels, with the parallel connection structure of coils, in order to reduce the size of the air gap created between the receiver coils of vehicles and transmitter coils installed in the floor area of buildings or parking lots [32]. The coils have ferrite core bars and are circular with the existence of an air gap in the middle with the functionality of transmitting and receiving the power from the vehicle to home and the other way around [31].

\section{Proposed Electric Vehicle Technology for V2H, V2B, V2G}

Plug-in battery-based EVs, plug-in hybrid EVs, and hydrogen FCEVs have the potential to be connected to the electric power grid, residential houses, and/or other buildings. However, the use of fuel cell-based EVs is not widely tested in real situations. The following sections provide details of EV technologies.

\subsection{Battery based EVs}

The battery electric vehicle (BEV) includes a battery pack for on-board or off-board charging [33], which powers the electric motor [34]. The main deficiency with regards to PEVs is that the total required electric energy for propulsion of the electric motor should be obtained through electrochemical energy conversion [35]. The key issue with battery-based EVs is battery degradation which can significantly affect the benefits of extending the V2-X technologies. Calendar ageing, SOC, depth of discharge (DOD), and temperature are some factors which cause battery degradation [36-38]. The physical battery degradation leads to a capacity fade, which causes a reduction in vehicle efficiency and increases in internal resistance [38]. As a result, the reduction in battery capacity reduces the driving range of vehicles and the remaining energy for $\mathrm{V} 2 \mathrm{H}-\mathrm{B}$ 
systems [10]. Over time a chemical side reactions capacity in the battery lead to capacity fade up to a three-fourth of its initial value in 16 years and eight months, without being used in battery-based cars [39]. An eight hours vehicle battery usage for V2H system showed two years reduction in pack lifetime compared to the use of battery packs solely for mixed-cycle driving [39]. Installation of a 50-150\% larger battery capacity in the examined EV led to an extension of battery life with a year and seven months of life reduction in the proposed V2H system [39]. As a result, a controlling strategy that optimizes the demand for battery storage energy usage can reduce degradation and increase the battery life [40].

\subsection{Plug-in Hybrid EVs}

The limitations of BEVs, such as long charging time, a fast discharge rate led to the design of plug-in hybrid electric vehicles (PHEVs) [41]. The battery pack is connected to the electric motor and can power the vehicle during the conventional engine operation or alone [42]. In PHEVs compared to hybrid electric vehicles, an additional battery charger and socket are added to obtain energy from the power grid [42]. PHEV, when the SOC of the battery is low, the conventional motor powers the vehicle until the battery replenishes to its maximum SOC level [42]. Also, during a low SOC, the battery pack in the process of the recuperation of the kinetic energy operates as a buffer in order to increase engine efficiency [43]. As high energy density and power density of installed energy storage systems (ESSs) are the main requirements for PHEVs, the combination of supercapacitors (SCs) and batteries is an effective way to extend the battery life [44], and increase the overall performance of the vehicle [44]. However, optimization of the battery size and the SC, as well as the implementation of an EMS, are necessary to ensure the battery is protected [44], from capacity and power fading [45].

\subsection{Hydrogen based EVs}

Fuel cell-based EVs power the vehicle by electrical energy generated from the chemical conversion of hydrogen [46]. Moreover, the fuel cell can be combined with other ESSs such as battery packs and SCs as an auxiliary energy source, which introduces fuel cell hybrid electric vehicles (FCHEVs) technology [47]. A novel fuel cell/ battery/ SC hybrid electric vehicle using PWM technique was proposed in [48], in order to provide three-phase current demonstrated a power efficiency of $96.2 \%$. Different combinations of the fuel cell with SC and battery packs are explained in [33, 49]. The combination of SC and battery reduces hydrogen fuel consumption [50], and the size of fuel cell stack [49]. Also, this combination enables the provision of instantaneous power required during acceleration and regenerative braking process[51].

Algorithms for various hybrid energy integration and interaction of proposed electric vehicles as well as a conventional and bio-based vehicle to buildings are evaluated and discussed in [52]. The technical interaction of different vehicles including hydrogen FCEVs, biofuel-based vehicles, battery electric vehicles and gasoline-based vehicles with buildings were presented in [52]. However, the investigation and implementation 
of these scenarios are not examined and compared in the existing buildings, in order to find the most optimal system.

\section{Recommendation for Future V2H, V2B, and V2G systems}

Based on the review, the following recommendations can be provided for a comprehensive V2-X solution:

Integration of V2-X solutions with FCHEVs, including fuel cell as well as ESSs (SC/ battery pack) can be the subject for future research. The consumption of hydrogen would be reduced in comparison with the integration of FCEV in the same situation. This is because the hybridization of fuel cell and SC/battery can improve the driving range and fuel economy of vehicles. However, the availability of hydrogen refueling stations can influence the decision about the reduction of hydrogen fuel requirement. Such a consideration can limit the advantages of fuel-cell based vehicles as a better solution for V2-X compared to PEVs.

Further research should be conducted in order to evaluate the need for a swappable battery for $\mathrm{V}^{2} \mathrm{~B}^{2}$ system integrated with FCEVs/FCHEVs. Furthermore, in FCHEVs with both SC and battery pack, the size of the battery pack is smaller compared to that of FCEV. As a result, the integration of V2-X solutions with FCHEV reduces the size of swappable battery required for the situations when the EVs provide power for a house and an office in another building. This reduction in the size of battery energy storage reduces the cost of the battery pack. However, an investigation is required to evaluate whether the smaller size of the battery pack can be used as an alternative to an energy storage system in terms of storing the generated energy by PV systems.

The swappable battery is suggested for the scenario considering the energy demand of a residential house and an office in a large building. The idea can be expanded to combine these vehicles with large commercial buildings such as universities with sustainable renewable energy systems. As the energy requirements of these buildings are much greater than residential buildings, the minimum number of EVs should be identified, in order to meet the NZEB concepts. Furthermore, the construction of parking lots creates the possibility of connecting vehicles-to-vehicles, which would enable vehicles to supply power to other vehicles and large buildings in addition to the residential houses of their owners. However, in this case, a combination of EVs (PHEVs, PEVs, FCEVs, and FCHEVs) can be used. Further research is needed to carry out the number of required swappable batteries when large buildings are taken into consideration. Furthermore, the use of swappable batteries would not be the best option, which increases the need for other storage solutions such as large energy storage systems as well as the existence of electrolyser/fuel cell stack in the building system.

\section{Conclusion}

Various types of EVs used for V2-X is operating as an auxiliary energy supplier in addition to renewable energy systems for smart houses and buildings. Integrating electric vehicles with buildings benefits from the use of off-site energy sources. These 
sources can be EV battery packs in addition to on-site renewable energy systems such as PV panels. The main aim of this integration was to shift the peak energy requirement of buildings to off-peak, meet the NZEB concepts, and provide backup power during a grid power outage. Problems such as, power quality and power losses caused by a long transmission line of $\mathrm{V} 2 \mathrm{G}$ technologies led to the introduction of $\mathrm{V} 2 \mathrm{H}$ (for a residential house) and V2B (for both residential and commercial buildings) solutions. Some studies introduced EVs as an alternative to large battery energy storage systems in buildings. While a few studies concluded the existence of a swappable battery pack similar to that of the vehicle was the best option. These studies expanded the V2H-B concepts by considering the energy demand of an office in a large building along with a residential house. Furthermore, local climate conditions should be taken into consideration, as the amount of generated energy from PV systems is significantly dependent on solar radiation. The FCEV was integrated with the grid, a PV system, and a house. The conclusion of this combination was that the hydrogen-fueled vehicle could reduce the negative impacts on the installed battery pack. This is because the battery was not the primary energy source and the main energy was provided by hydrogen. The combination of V2-X technologies with EVs can be expanded to a greater number of houses, buildings, and the power grid. Consequently, recommendations have been made in regard to further studies which evaluate whether fuel cell-based vehicles and swappable batteries are the best solutions for larger buildings by considering economic, required services, technology, and environmental impacts concerns.

\section{$7 \quad$ References}

1. D. Aelenei, R. A. Lopes, L. Aelenei, and H. Gonçalves, "Investigating the potential for energy flexibility in an office building with a vertical BIPV and a PV roof system," Renewable Energy, vol. 137, pp. 189-197, 2019, doi: 10.1016/j.renene.2018.07.140.

2. Y. Zhou and S. Cao, "Investigation of the flexibility of a residential net-zero energy building (NZEB) integrated with an electric vehicle in Hong Kong," Energy Procedia, vol. 158, pp. 2567-2579, 2019.

3. H. Dagdougui, A. Ouammi, and L. A. Dessaint, "Peak Load Reduction in a Smart Building Integrating Microgrid and V2B-Based Demand Response Scheme," IEEE Systems Journal, vol. 13, no. 3, pp. 3274-3282, 2019, doi: 10.1109/jsyst.2018.2880864.

4. O. Erdinc, "Economic impacts of small-scale own generating and storage units, and electric vehicles under different demand response strategies for smart households," Applied Energy, vol. 126, pp. 142-150, 2014, doi: 10.1016/j.apenergy.2014.04.010.

5. D. Guo and C. Zhou, "Potential performance analysis and future trend prediction of electric vehicle with V2G/V2H/V2B capability," AIMS Energy, vol. 4, no. 2, pp. 331-346, 2016, doi: 10.3934/energy.2016.2.331.

6. D. Thomas, O. Deblecker, and C. S. Ioakimidis, "Optimal operation of an energy management system for a grid-connected smart building considering photovoltaics' uncertainty and stochastic electric vehicles' driving schedule," Applied Energy, vol. 210, pp. 1188-1206, 2018, doi: 10.1016/j.apenergy.2017.07.035.

7. H. Mehrjerdi and R. Hemmati, "Coordination of vehicle-to-home and renewable capacity resources for energy management in resilience and self-healing building," Renewable Energy, vol. 146, pp. 568-579, 2020, doi: 10.1016/j.renene.2019.07.004. 
8. S. Rao et al., "Plug-in Hybrid Electric Vehicle energy system using home-to-vehicle and vehicle-to-home: Optimizat on of power converter operation," in 2013 IEEE Transportation Electrification Conference and Expo (ITEC), 2013: IEEE, pp. 1-6.

9. M. S. Shemami, M. S. Alam, and M. S. J. Asghar, "Reliable Residential Backup Power Control System Through Home to Plug-In Electric Vehicle (H2V)," Technology and Economics of Smart Grids and Sustainable Energy, vol. 3, no. 1, 2018, doi: 10.1007/s40866018-0046-9.

10. N. S. Pearre and H. Ribberink, "Review of research on V2X technologies, strategies, and operations," Renewable and Sustainable Energy Reviews, vol. 105, pp. 61-70, 2019, doi: 10.1016/j.rser.2019.01.047.

11. K. M. Tan, V. K. Ramachandaramurthy, and J. Y. Yong, "Integration of electric vehicles in smart grid: A review on vehicle to grid technologies and optimization techniques," Renewable and Sustainable Energy Reviews, vol. 53, pp. 720-732, 2016, doi: 10.1016/j.rser.2015.09.012.

12. J. H. M. Langbroek, J. P. Franklin, and Y. O. Susilo, "When do you charge your electric vehicle? A stated adaptation approach," Energy Policy, vol. 108, pp. 565-573, 2017, doi: 10.1016/j.enpol.2017.06.023.

13. S. Al-Rubaye, A. Al-Dulaimi, and Q. Ni, "Power interchange analysis for reliable vehicleto-grid connectivity," IEEE Communications Magazine, vol. 57, no. 8, pp. 105-111, 2019.

14. J. D. A. Castellanos, H. D. V. Rajan, A.-K. Rohde, D. Denhof, and M. Freitag, "Design and simulation of a control algorithm for peak-load shaving using vehicle to grid technology," SN Applied Sciences, vol. 1, no. 9, p. 951, 2019.

15. M. Alirezaei, M. Noori, and O. Tatari, "Getting to net zero energy building: Investigating the role of vehicle to home technology," Energy and Buildings, vol. 130, pp. 465-476, 2016, doi: 10.1016/j.enbuild.2016.08.044.

16. D. P. Tuttle, R. L. Fares, R. Baldick, and M. E. Webber, "Plug-in vehicle to home (V2H) duration and power output capability," in 2013 IEEE Transportation Electrification Conference and Expo (ITEC), 2013: IEEE, pp. 1-7.

17. J. Pinto et al., "Bidirectional battery charger with grid-to-vehicle, vehicle-to-grid and vehicle-to-home technologies," in IECON 2013-39th Annual Conference of the IEEE Industrial Electronics Society, 2013: IEEE, pp. 5934-5939.

18. C. Liu, K. T. Chau, D. Wu, and S. Gao, "Opportunities and Challenges of Vehicle-to-Home, Vehicle-to-Vehicle, and Vehicle-to-Grid Technologies," Proceedings of the IEEE, vol. 101, no. 11, pp. 2409-2427, 2013, doi: 10.1109/jproc.2013.2271951.

19. G. Barone, A. Buonomano, F. Calise, C. Forzano, and A. Palombo, "Building to vehicle to building concept toward a novel zero energy paradigm: Modelling and case studies," Renewable and Sustainable Energy Reviews, vol. 101, pp. 625-648, 2019, doi: 10.1016/j.rser.2018.11.003.

20. J. García-Villalobos, I. Zamora, J. I. San Martín, I. Junquera, and P. Eguía, "Delivering Energy from PEV batteries: V2G, V2B and V2H approaches," Renewable Energy and Power Quality Journal, pp. 89-94, 2015, doi: 10.24084/repqj13.247.

21. F. Berthold, A. Ravey, B. Blunier, D. Bouquain, S. Williamson, and A. Miraoui, "Design and Development of a Smart Control Strategy for Plug-In Hybrid Vehicles Including Vehicle-to-Home Functionality," IEEE Transactions on Transportation Electrification, vol. 1, no. 2, pp. 168-177, 2015, doi: 10.1109/tte.2015.2426508.

22. V. Monteiro, J. Catalao, T. Sousa, J. Pinto, M. Mezaroba, and J. Afonso, "Improved Voltage Control for the Electric Vehicle Operation in V2H Mode as an Off-Line UPS in the Context of Smart Homes," EAI Endorsed Transactions on Energy Web, vol. 0, no. 0, 2018, doi: 10.4108/eai.13-7-2018.160980. 
23. V. Monteiro, J. G. Pinto, and J. L. Afonso, "Operation Modes for the Electric Vehicle in Smart Grids and Smart Homes: Present and Proposed Modes," IEEE Transactions on Vehicular Technology, vol. 65, no. 3, pp. 1007-1020, 2016, doi: 10.1109/tvt.2015.2481005.

24. F. Berthold et al., "Optimization of a battery charging schedule in a net zero energy house using vehicle-to-home functionality," in Proc. eSim14, IBPSA, 2014.

25. H. Shin and R. Baldick, "Plug-In Electric Vehicle to Home (V2H) Operation Under a Grid Outage," IEEE Transactions on Smart Grid, vol. 8, no. 4, pp. 2032-2041, 2017, doi: 10.1109/tsg.2016.2603502.

26. A. Buonomano, "Building to Vehicle to Building concept: A comprehensive parametric and sensitivity analysis for decision making aims," Applied Energy, vol. 261, p. 114077, 2020.

27. C. B. Robledo, V. Oldenbroek, F. Abbruzzese, and A. J. M. van Wijk, "Integrating a hydrogen fuel cell electric vehicle with vehicle-to-grid technology, photovoltaic power and a residential building," Applied Energy, vol. 215, pp. 615-629, 2018, doi: 10.1016/j.apenergy.2018.02.038.

28. H. Cheng, H. Chen, and Q. Wang, "An Integrated Drive Power Converter Topology for Plug-in Hybrid Electric Vehicle with G2V, V2G and V2H Functions," in 2019 22nd International Conference on Electrical Machines and Systems (ICEMS), 2019: IEEE, pp. 1-6.

29. A. R. Bhatti, Z. Salam, M. J. B. A. Aziz, K. P. Yee, and R. H. Ashique, "Electric vehicles charging using photovoltaic: Status and technological review," Renewable and Sustainable Energy Reviews, vol. 54, pp. 34-47, 2016, doi: 10.1016/j.rser.2015.09.091.

30. A. Yamamoto, H. Omori, M. Tsuno, J. Nohara, N. Kimura, and T. Morizane, "A New Type of Single-Ended Wireless V2H System with Dual-Active Phase-Shift Control," in 2018 IEEE International Power Electronics and Application Conference and Exposition (PEAC), 2018: IEEE, pp. 1-6.

31. N. Mukaiyama, H. Omeri, N. Kimura, T. Morizane, M. Tsuno, and M. Nakaoka, "A novel type of bidirectional IPT with a dual-active seamless controlled single-ended converter for wireless V2H," in 2017 19th International Conference on Electrical Drives and Power Electronics (EDPE), 2017: IEEE, pp. 53-58.

32. C. Panchal, S. Stegen, and J. Lu, "Review of static and dynamic wireless electric vehicle charging system," Engineering science and technology, an international journal, vol. 21, no. 5, pp. 922-937, 2018.

33. H. S. Das, C. W. Tan, and A. H. M. Yatim, "Fuel cell hybrid electric vehicles: A review on power conditioning units and topologies," Renewable and Sustainable Energy Reviews, vol. 76, pp. 268-291, 2017, doi: 10.1016/j.rser.2017.03.056.

34. S. Manzetti and F. Mariasiu, "Electric vehicle battery technologies: From present state to future systems," Renewable and Sustainable Energy Reviews, vol. 51, pp. 1004-1012, 2015, doi: 10.1016/j.rser.2015.07.010.

35. J. Aghaei, A. E. Nezhad, A. Rabiee, and E. Rahimi, "Contribution of Plug-in Hybrid Electric Vehicles in power system uncertainty management," Renewable and Sustainable Energy Reviews, vol. 59, pp. 450-458, 2016, doi: 10.1016/j.rser.2015.12.207.

36. A. Ahmadian, M. Sedghi, A. Elkamel, M. Fowler, and M. Aliakbar Golkar, "Plug-in electric vehicle batteries degradation modeling for smart grid studies: Review, assessment and conceptual framework," Renewable and Sustainable Energy Reviews, vol. 81, pp. 2609-2624, 2018, doi: 10.1016/j.rser.2017.06.067.

37. T. Harighi, R. Bayindir, S. Padmanaban, L. Mihet-Popa, and E. Hossain, "An Overview of Energy Scenarios, Storage Systems and the Infrastructure for Vehicle-to-Grid Technology," Energies, vol. 11, no. 8, 2018, doi: 10.3390/en11082174. 
38. K. Uddin, M. Dubarry, and M. B. Glick, "The viability of vehicle-to-grid operations from a battery technology and policy perspective," Energy Policy, vol. 113, pp. 342-347, 2018, doi: 10.1016/j.enpol.2017.11.015.

39. K. Darcovich, S. Recoskie, H. Ribberink, F. Pincet, and A. Foissac, "Effect on battery life of vehicle-to-home electric power provision under Canadian residential electrical demand," Applied Thermal Engineering, vol. 114, pp. 1515-1522, 2017, doi: 10.1016/j.applthermaleng.2016.07.002.

40. S. Habib, M. Kamran, and U. Rashid, "Impact analysis of vehicle-to-grid technology and charging strategies of electric vehicles on distribution networks - A review," Journal of Power Sources, vol. 277, pp. 205-214, 2015, doi: 10.1016/j.jpowsour.2014.12.020.

41. R. Á. Fernández, F. B. Cilleruelo, and I. V. Martínez, "A new approach to battery powered electric vehicles: A hydrogen fuel-cell-based range extender system," International Journal of Hydrogen Energy, vol. 41, no. 8, pp. 4808-4819, 2016, doi: 10.1016/j.ijhydene.2016.01.035.

42. M. F. M. Sabri, K. A. Danapalasingam, and M. F. Rahmat, "A review on hybrid electric vehicles architecture and energy management strategies," Renewable and Sustainable Energy Reviews, vol. 53, pp. 1433-1442, 2016, doi: 10.1016/j.rser.2015.09.036.

43. Z. Chen, R. Xiong, C. Wang, and J. Cao, "An on-line predictive energy management strategy for plug-in hybrid electric vehicles to counter the uncertain prediction of the driving cycle," Applied Energy, vol. 185, pp. 1663-1672, 2017, doi: 10.1016/j.apenergy.2016.01.071.

44. Z. Song, X. Zhang, J. Li, H. Hofmann, M. Ouyang, and J. Du, "Component sizing optimization of plug-in hybrid electric vehicles with the hybrid energy storage system," Energy, vol. 144, pp. 393-403, 2018, doi: 10.1016/j.energy.2017.12.009.

45. C. M. Martinez, X. Hu, D. Cao, E. Velenis, B. Gao, and M. Wellers, "Energy Management in Plug-in Hybrid Electric Vehicles: Recent Progress and a Connected Vehicles Perspective," IEEE Transactions on Vehicular Technology, vol. 66, no. 6, pp. 4534-4549, 2017, doi: 10.1109/tvt.2016.2582721.

46. O. Z. Sharaf and M. F. Orhan, "An overview of fuel cell technology: Fundamentals and applications," Renewable and Sustainable Energy Reviews, vol. 32, pp. 810-853, 2014.

47. T. Wilberforce et al., "Developments of electric cars and fuel cell hydrogen electric cars," International Journal of Hydrogen Energy, vol. 42, no. 40, pp. 25695-25734, 2017, doi: 10.1016/j.ijhydene.2017.07.054.

48. H. Fathabadi, "Novel fuel cell/battery/supercapacitor hybrid power source for fuel cell hybrid electric vehicles," Energy, vol. 143, pp. 467-477, 2018, doi: 10.1016/j.energy.2017.10.107.

49. V. K. Kasimalla, N. S. G, and V. Velisala, "A review on energy allocation of fuel cell/battery/ultracapacitor for hybrid electric vehicles," International Journal of Energy Research, vol. 42, no. 14, pp. 4263-4283, 2018, doi: 10.1002/er.4166.

50. T. Li, H. Liu, D. Zhao, and L. Wang, "Design and analysis of a fuel cell supercapacitor hybrid construction vehicle," International Journal of Hydrogen Energy, vol. 41, no. 28, pp. 12307-12319, 2016, doi: 10.1016/j.ijhydene.2016.05.040.

51. S. Ahmadi, S. M. T. Bathaee, and A. H. Hosseinpour, "Improving fuel economy and performance of a fuel-cell hybrid electric vehicle (fuel-cell, battery, and ultra-capacitor) using optimized energy management strategy," Energy Conversion and Management, vol. 160, pp. 74-84, 2018, doi: 10.1016/j.enconman.2018.01.020.

52. Y. Zhou, S. Cao, J. L. Hensen, and P. D. Lund, "Energy integration and interaction between buildings and vehicles: A state-of-the-art review," Renewable and Sustainable Energy Reviews, vol. 114, p. 109337, 2019. 